\title{
EKSTRAKSI KATEKIN DARI DAUN GAMBIR (Uncaria gambir roxb) DENGAN METODE MASERASI
}

\author{
Desta Donna Putri Damanik, Nurhayati Surbakti, Rosdanelli Hasibuan \\ Departemen Teknik Kimia, Fakultas Tekknik, Universitas Sumatera Utara \\ Jl. Almamater Kampus USU Medan 20155, Indonesia \\ Email : Desta_Df11@yahoo.co.id
}

\begin{abstract}
Abstrak
Katekin merupakan komponen utama di dalam tanaman gambir. Selain katekin ada beberapa komponen lain seperti asam kateku tanat, kuersetin, kateku merah, gambir flouresin, lemak dan lilin. Produksi gambir di Indonesia lebih dari $80 \%$ berasal dari provinsi Sumatera Barat dan Sumatera Utara, terutama di Kabupaten Limapuluh dan Kabupaten Pakpak Bharat. Ekstraksi katekin dari daun gambir ini dilakukan dengan cara maserasi yaitu perendaman dengan pelarut polar. Maserasi dilakukan dengan variasi suhu yaitu, $30^{\circ} \mathrm{C}, 40^{\circ} \mathrm{C}, 60^{\circ} \mathrm{C}$, dan $80^{\circ} \mathrm{C}$; waktu maserasi yaitu $1 \mathrm{jam}, 6 \mathrm{jam}, 12 \mathrm{jam}$, dan $24 \mathrm{jam}$; dan jenis pelarut yaitu akuades, etanol $96 \%$, etil asetat $95 \%$, dan campuran antara etanol $96 \%$ dan etil asetat $95 \%$ (1:1). Hasil maserasi disaring untuk mendapatkan filtratnya yang kemudian dipekatkan dengan rotary vacuum evaporator untuk diuji kadar katekin, kadar air dan kadar abu. Dari penelitian ini kadar katekin tertinggi diperoleh dari kondisi operasi suhu maserasi $60^{\circ} \mathrm{C}$ dengan waktu maserasi 6 jam dan pelarut yang digunakan etil asetat 95\% yaitu sebesar $87,14 \%$ dengan kadar air sebesar $0,925 \%$ dan kadar abu sebesar $0,04 \%$.
\end{abstract}

Kata kunci: daun gambir, katekin, maserasi

\begin{abstract}
Catechins are a major components in the plant gambier. Beside catechins, there are several other components such as acid catechu tannat, quersetin, red catechu, gambier flouresin, fats and waxes. More than $80 \%$ of gambier production in Indonesia comes from the province of West Sumatra and North Sumatra, mainly in Limapuluh and Pakpak Bharat. Extraction of catechins from gambir leaf was performed by means of maceration that is soaking with a solvent polar. Maceration is carried out by temperature variations, $30^{\circ} \mathrm{C}, 40^{\circ} \mathrm{C}, 60^{\circ} \mathrm{C}$ and $80^{\circ} \mathrm{C}$; maceration of time that is 1 hour, 6 hours, 12 hours, and 24 hours; and the type of solvent is aquadest, $96 \%$ ethanol, $95 \%$ ethyl acetate, and a mixture of $96 \%$ ethanol and $95 \%$ ethyl acetate $(1: 1)$. The results were filtered to obtain the filtrate which is then concentrated by rotary vacuum evaporator to test the levels of catechins, moisture content, and ash content. Based on this research the highest levels of catechins obtained the maceration temperature operating conditions of $60^{\circ} \mathrm{C}$ with a time of 6 hours maceration and used $95 \%$ ethyl acetate as solvents in the amount of $87.14 \%$ to $0.925 \%$ moisture content and ash content of $0.04 \%$.
\end{abstract}

Keywords: leaf gambier, catechins, maceration

\section{Pendahuluan}

Gambir mengandung katekin yang merupakan komponen utama. Katekin merupakan senyawa flavonoid yang dapat ditemukan pada teh hijau, teh hitam, gambir, anggur dan tanaman pangan lainnya seperti buah - buahan dan kakao [6]. Katekin larut dalam alkohol dingin, etil asetat, air panas serta asam asetat glasial dan aseton dan berguna sebagai antibiotic [4]. Mutu gambir antara lain ditentukan oleh kadar katekin sebagaimana tercantum dalam stándar mutu SNI 01 3391-2000, dapat dilihat pada tabel $1[2]$.

\section{Teori}

Ekstraksi merupakan salah satu metoda pemisahan zat terlarut dengan pelarutnya berdasarkan titik didih pelarut. Metode ekstraksi terbagi atas 2 cara, yaitu:

a. Maserasi

Maserasi merupakan cara ekstraksi yang paling sederhana. Bahan simpilisia yang digunakan dihaluskan berupa serbuk kasar, dilarutkan dengan bahan pengekstraksi. [10].

b. Soxhletasi

Soxhletasi merupakan cara ekstraksi yang dilakukan dalam sebuah alat yang 
disebut soxhlet dengan pelarut polar berdasarkan titik didihnya.

Pemilihan metode maserasi pada penelitian ini dikarenakan senyawa katekin rentan terhadap panas sehingga tidak baik menggunakan metode soxhlet. Hal ini didukung oleh penelitian Cheong dkk (2005) bahwa konsentrasi senyawa katekin mengalami penurunan pada metode soxhlet dibandingkan dengan metode maserasi [3].

Tabel 1 Mutu gambir menurut Standar Nasional Indonesia.

\begin{tabular}{|l|l|}
\hline \multicolumn{1}{|c|}{ Karakteristik } & \multicolumn{1}{c|}{ Mutu I } \\
\hline Kadar air (\%) & Maks.17,0 \\
\hline Kadar abu (\%) & Maks. 7,0 \\
\hline Kadar katekin (\%) & Min. 40,0 \\
\hline
\end{tabular}

\section{Pelarut Ekstrasi}

Pelarut yang biasa digunakan untuk ekstraksi diantaranya adalah metanol, etanol, etil asetat, aseton dan asetonitril dengan air.

Pemilihan pelarut pada proses ekstraksi dilakukan dengan alasan karena pelarut mampu melarutkan senyawa yang akan diekstrak, mudah dipisahkan dan dimurnikan kembali [1].

\section{Suhu Ekstraksi}

Suhu ekstraksi yang terbaik dilakukan pada kisaran suhu $20^{\circ} \mathrm{C}-80^{\circ} \mathrm{C}$ tetapi suhu yang digunakan harus dibawah titik didih pelarut yang digunakan [8].

\section{Metodologi Penelitian \\ Prosedur Percobaan \\ 1. Preparasi Bahan}

Daun gambir segar yang dipetik dari tanaman gambir sebanyak 3,2 kg yang terdiri dari daun muda, daun tua dibagi dalam 4 bagian untuk diekstraksi dengan 4 variasi pelarut ekstraksi, yaitu akuades, etanol 96\%, etil asetat $95 \%$, dan etil asetat 95\%:etanol $96 \%$ (1:1). Masing - masing terdiri dari $50 \mathrm{gr}$ daun gambir untuk dibagi-bagi ke dalam 4 bagian untuk variasi suhu maserasi dan waktu maserasi. Sampel diekstraksi dengan perbandingan bahan baku:pelarut (1:6) (w/v).

\section{Ekstraksi Daun Gambir}

Daun gambir yang telah dihaluskan ditimbang sebanyak 50 gr dan dilarutkan pada pelarut (akuades, etanol 96\%, etil asetat 95\%, dan etil asetat 95\%:etanol 96\% (1:1)) sebanyak $300 \mathrm{ml}$. Sampel kemudian dipanaskan di dalam waterbath selama 60 menit. Setelah itu sampel didiamkan di tempat gelap selama (1 jam, 6 jam, 12 jam, dan 24 jam). Kemudian disaring dan hasil filtratnya di uji kadar katekin, kadar air, dan kadar abu [2].

\section{Hasil dan Pembahasan}

Berdasarkan hasil penelitian ekstraksi daun gambir diketahui bahwa terdapat interaksi sangat nyata antara jenis pelarut, suhu maserasi dan waktu maserasi terhadap kadar katekin, kadar air dan kadar abu. Perubahan kadar katekin, kadar air dan kadar abu akibat jenis pelarut, suhu maserasi dan waktu maserasi dapat dilihat dibawah ini.

Pengaruh Berbagai Jenis Pelarut, Suhu Maserasi dan waktu Maserasi Terhadap Kadar Katekin

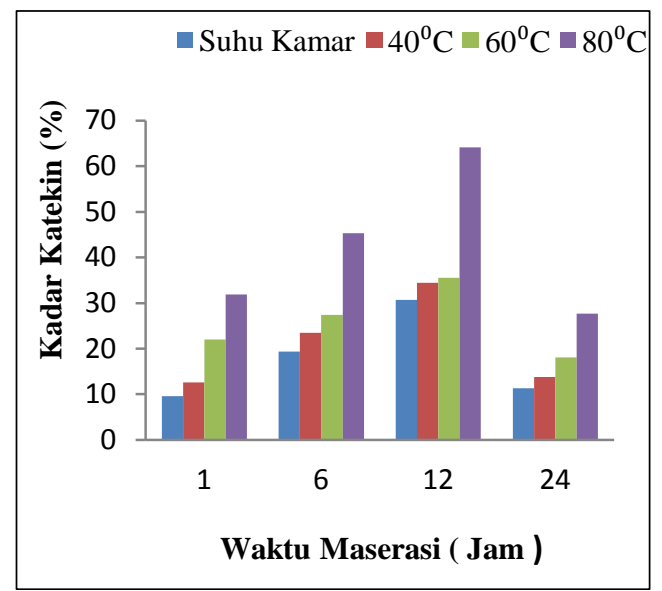

Gambar 1. Pengaruh suhu dan waktu maserasi terhadap kadar katekin pada pelarut akuades

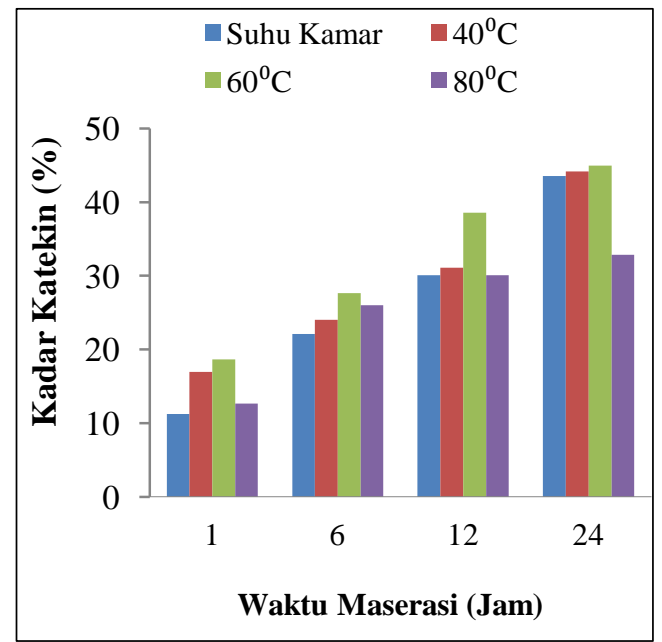

Gambar 2 Pengaruh suhu dan waktu maserasi terhadap kadar katekin pada pelarut etanol $96 \%$ 


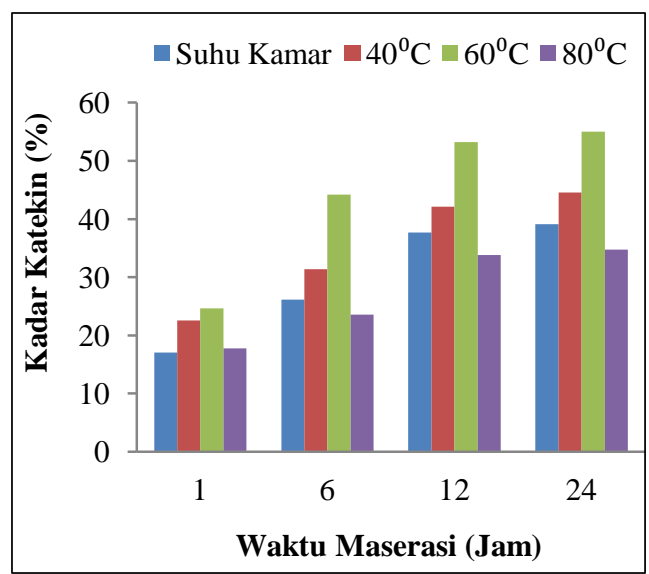

Gambar 3. Pengaruh suhu dan waktu maserasi terhadap kadar katekin pada pelarut etanol 96\%:etil asetat $95 \%(1: 1)$

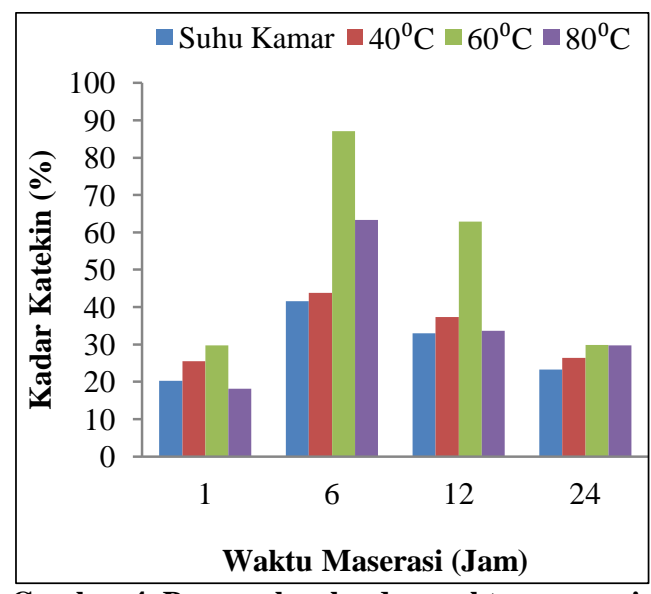

Gambar 4. Pengaruh suhu dan waktu maserasi terhadap kadar katekin pada pelarut etil asetat 95\%

Dari Gambar 1-4 diketahui bahwa kadar katekin tertinggi terdapat pada pelarut etil asetat $95 \%$ dengan suhu maserasi $60^{\circ} \mathrm{C}$ dan waktu Maserasi 6 jam yaitu sebesar $87,14 \%$ dan kadar katekin terendah terdapat pada pelarut akuades dengan suhu kamar maserasi dan waktu maserasi 1 jam yaitu sebesar $9,83 \%$.

Hal ini sesuai dengan penelitian Sousa (2008) bahwa pemilihan pelarut yang terbaik pada proses senyawa yang akan diekstrak yaitu pelarut yang mudah dipisahkan (menguap) dan dimurnikan kembali [9]. Semakin tinggi suhu maserasi maka kecepatan perpindahan masa dari solut ke solven akan semakin tinggi karena suhu mempengaruhi nilai koefisien transfer masa dari suatu komponen. Tetapi penurunan kadar katekin ini diakibatkan oleh suhu maserasi yang lebih besar dari titik didih pelarutnya [4] Semakin lama waktu ekstraksi, kesempatan untuk bersentuhan antara solut dengan solven semakin besar sehingga hasil ekstraksi semakin bertambah banyak [7].

Pengaruh Berbagai Jenis Pelarut, suhu maserasi dan waktu Maserasi Terhadap Kadar Air

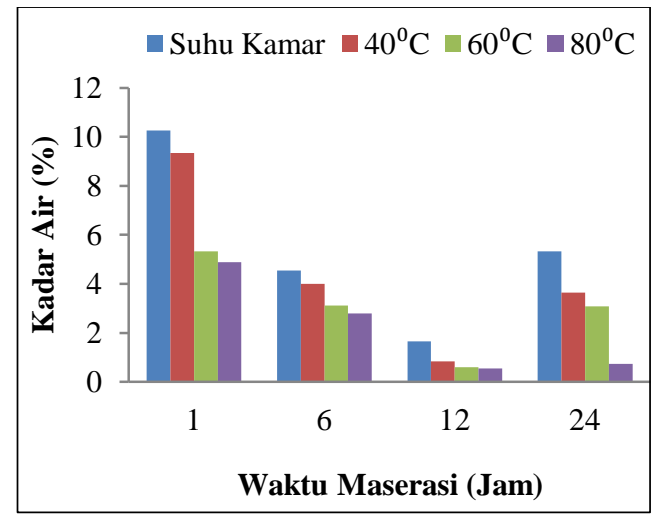

Gambar 5. Pengaruh suhu dan waktu maseras terhadap kadar air pada pelarut akuades

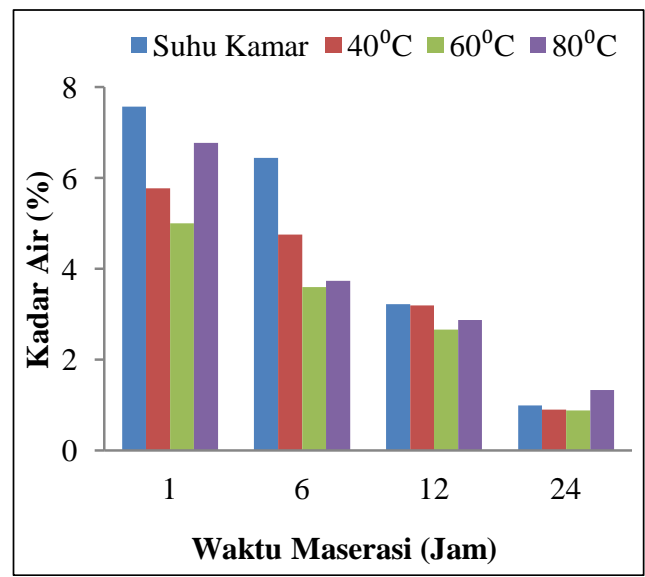

Gambar 6. Pengaruh suhu dan waktu maserasi terhadap kadar air pada pelarut etanol $96 \%$

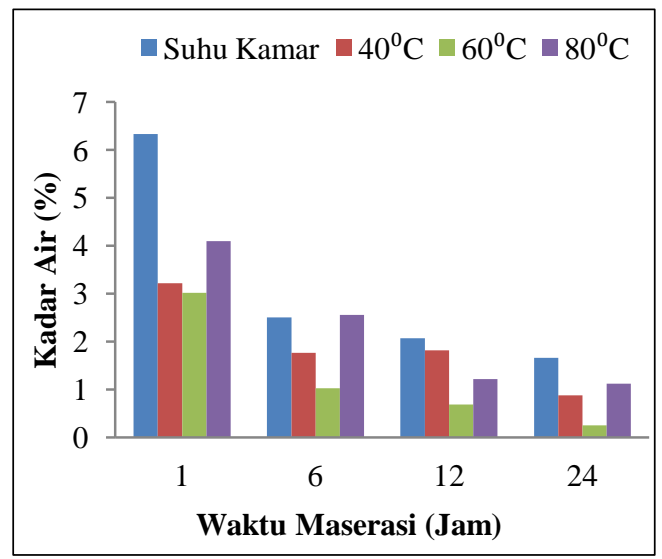

Gambar 7. Pengaruh suhu dan waktu maserasi terhadap kadar air pada pelarut etanol 96\%: etil asetat $95 \%(1: 1)$ 


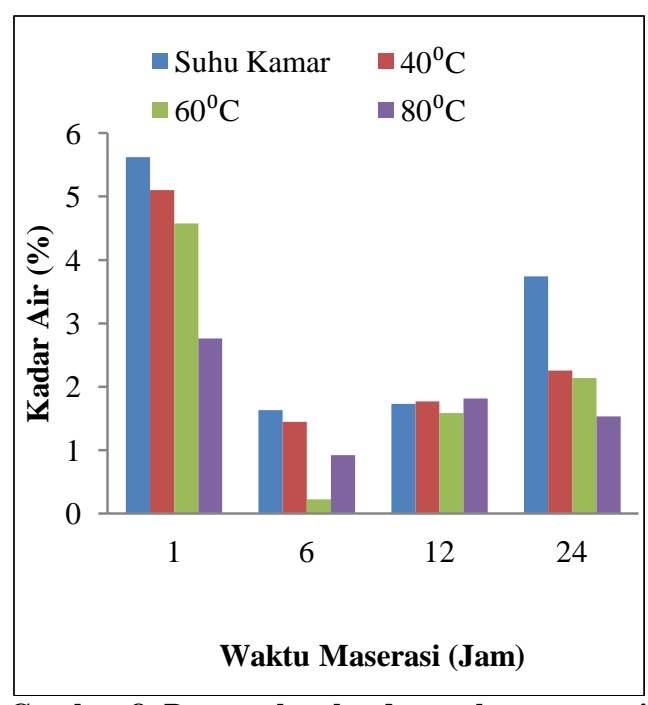

Gambar 8. Pengaruh suhu dan waktu maserasi terhadap kadar air pada pelarut etil asetat $95 \%$

Dari Gambar 5-8 diketahui bahwa kadar air yang tertinggi terdapat pada pelarut akuades dengan suhu kamar dan waktu Maserasi 1 jam yaitu sebesar 10,225\% dan kadar air terendah terdapat pada pelarut etil asetat $95 \%$ dengan suhu maserasi $60^{\circ} \mathrm{C}$ dan waktu maserasi 6 jam yaitu sebesar $0,225 \%$.

Nilai kadar air yang diperoleh dari pelarut setiap pelarut tersebut masih sesuai dengan kadar air Mutu gambir menurut Standar Nasional Indonesia (SNI 01-3392000) yaitu kurang dari 17\% [2].

Pengaruh Berbagai Jenis Pelarut, suhu maserasi dan waktu Maserasi Terhadap Kadar Abu

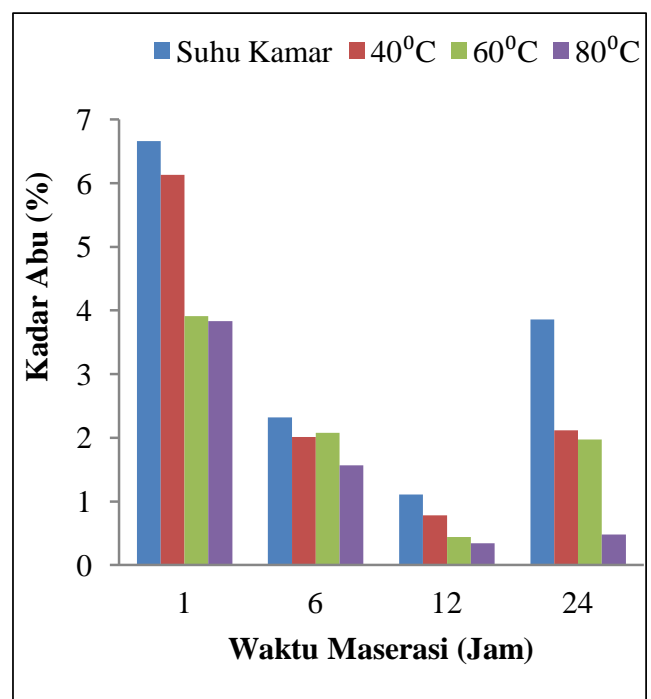

Gambar 9. Pengaruh suhu dan waktu maserasi terhadap kadar abu pada pelarut akuades

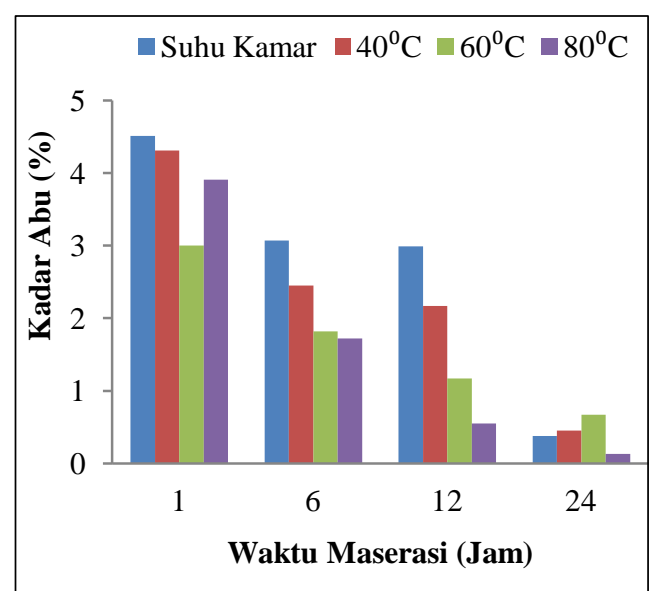

Gambar 10. Pengaruh suhu dan waktu maserasi terhadap kadar abu pada pelarut etanol $96 \%$

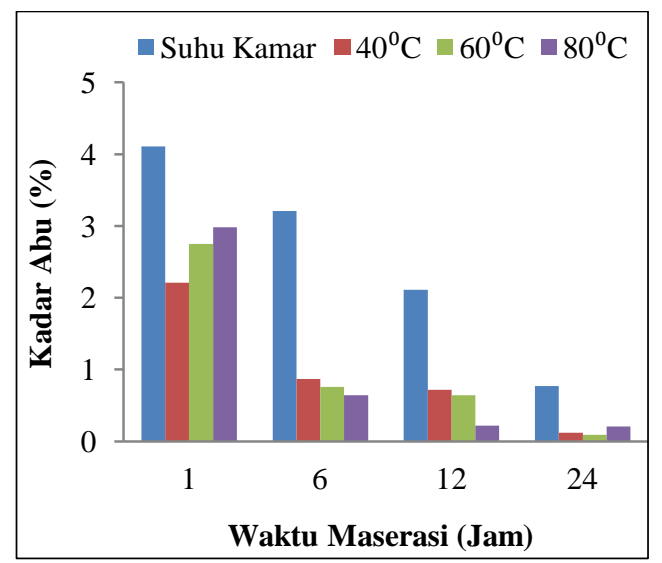

Gambar 11. Pengaruh suhu dan waktu maserasi terhadap kadar abu pada pelarut etanol 96\%:etil asetat 95\% (1:1)

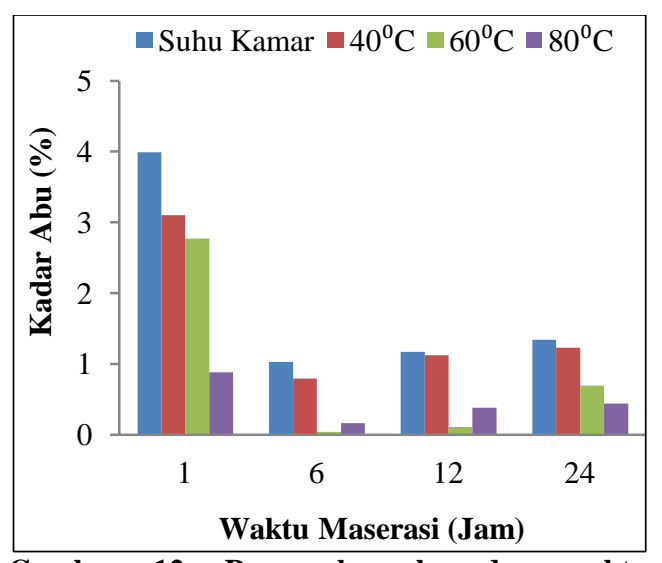

Gambar 12. Pengaruh suhu dan waktu maserasi terhadap kadar abu pada pelarut etil asetat $95 \%$

Dari Gambar 9-12 diketahui bahwa kadar abu yang tertinggi terdapat pada pelarut akuades dengan suhu kamar dan waktu Maserasi 1 jam yaitu sebesar 6,66\% dan 
kadar air terendah terdapat pada pelarut etil asetat $95 \%$ dengan suhu maserasi $60^{\circ} \mathrm{C}$ dan waktu maserasi 6 jam yaitu sebesar $0,04 \%$.

Nilai kadar abu yang diperoleh dari pelarut etil asetat $95 \%$ tersebut masih sesuai dengan kadar abu Mutu gambir menurut Standar Nasional Indonesia (SNI 01-3392000) yaitu kurang dari 7\% [2].

\section{Kesimpulan}

1. Kadar katekin tertinggi diperoleh dari pelarut etil asetat $95 \%$ dengan kondisi operasi suhu maserasi $60^{\circ} \mathrm{C}$ dan lama maserasi 6 jam yaitu sebesar $87,14 \%$.

2. Kadar air tertinggi diperoleh dari akuades dengan kondisi operasi suhu kamar dan lama maserasi 1 jam yaitu sebesar $10,255 \%$.

3. Kadar abu tertinggi diperoleh dari akuades dengan kondisi operasi suhu kamar dan lama maserasi 1 jam yaitu sebesar $6,66 \%$.

4. Ekstrak daun gambir menghasilkan kadar katekin, kadar air, dan kadar abu yang memenuhi standar mutu I gambir maka dapat dimanfaatkan sebagai antioksidan ataupun obat-obatan.

\section{Daftar Pustaka}

[1] Ansel H. C, Pengantar Bentuk Sediaan Farmasi, Edisi 4, Press UI, Jakarta, 1989.

[2] Balai Penelitian dan Pengembangan Industri Padang, Standar Nasional (SNI) Gambir, 01-3391-2000, Departemen Perindustrian dan Perdagangan, 2000.

[3] Cheong, M. H, Park, M. H., Kang, G. W, Ko, J, H, dan Seo, Y, J, Determination of Catechin Compounds in Korea Green Tea Influsions Under Varios Extraction Condition by High Performance Liquid Chomatrography, Bulletin of The Korea Chemical Society $26 \mathrm{Vol}$ (5): 747 - 754, 2005.

[4] Geankoplis, C,J, Transport Processes and Unit Operation, Allyn and Dalcon Inc, Boston, USA, 1983.

[5] Hayani, Eni, Analisis Kadar Catechin dari Gambir Dengan Berbagai Metode, Buletin Teknik Pertanian, Vol (1) : 3132, 1983.

[6] Natsume, M. Dkk, Analysis of Polyphenols in Cacao Liquor, Cocoa, and Chocolate by Normal - Phase and
Reversed - Phase HPLC, Biotechnol, Vol(64):2581-2587, Diahlibahasakan oleh Liris Mahadewi Rachimullah. Universitas Muhamadiyah,Surakarta, 2000.

[7] Purwani, M, V, Suyanti, dan Muhadi, Ekstraksi Konsentrat Neodimium Memakai Asam Di - 2 - Etil Heksil Fosfat, Seminar Nasional IV SDM Teknologi Nuklir, Yogyakarta, 2008.

[8] Setiyowati, V.,Karakterisasi dan Pengujian Aktivitas Antioksidan Tabelt Effervescent Ekstrak Teh Hijau Pada Lama Ekstraksi dan Jenis Bahan Pengisi yang Berbeda, Skripsi Mahasiswa Jurusan Teknologi Hasil Pertanian, Falkultas Teknologi Pertanian, Universitas Brawijaya, 2007

[9] Sousa, A., dkk.,Effect Of Solvent And Extraction Temperatures On The Antioxident Potential of Traditional Stoned Table Olives Alcaparras, Vol (41):739-745, Diahlibahasakan oleh Liris Mahadewi Rachimullah. Universitas Muhamadiyah, Surakarta, 2008.

[10] Voight, R., Buku Pelajaran Teknologi Ekstraksi, Diahlibahasakan oleh Soewandhi, S. N. Edisi 5, Gadja Mada University Press, Yogyakarta, 1995. 